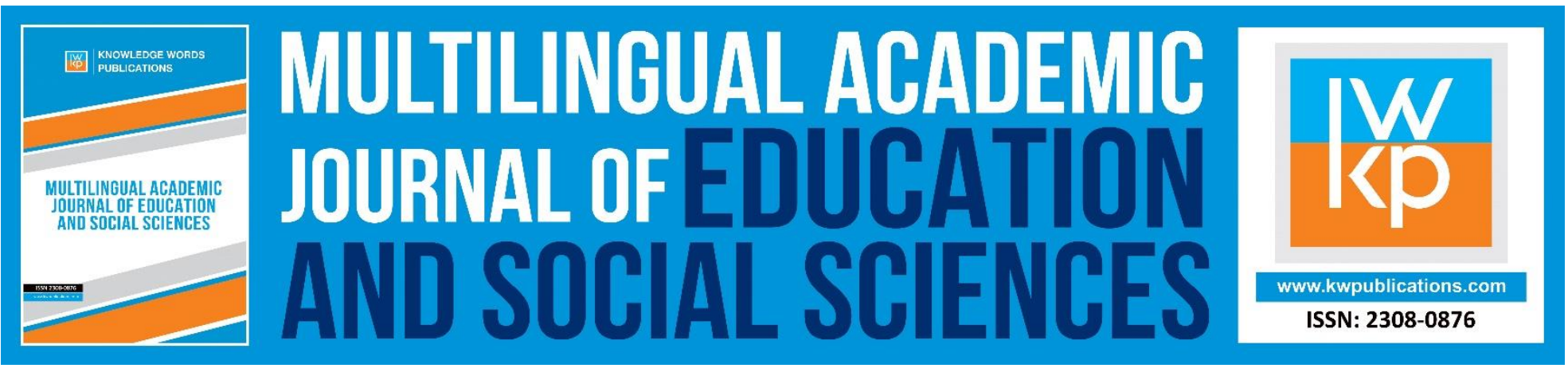

\title{
Children's Drawings and the Grammar of Visual Design: Pedagogical Application of the Depiction of the "Other" in Pre-school Children's Drawings
}

\section{Evmorfia Kipouropoulou}

To Link this Article: http://dx.doi.org/10.46886/MAJESS/v8-i1/7274

DOI: 10.46886/MAJESS/v8-i1/7274

Received: 27 March 2020, Revised: 29 April 2020, Accepted: 14 May 2020

Published Online: 15 June 2020

In-Text Citation: (Kipouropoulou, 2020)

To Cite this Article: Kipouropoulou, E. (2020). Children's Drawings and the Grammar of Visual Design:

Pedagogical Application of the Depiction of the "Other" in Pre-school Children's Drawings. Multilingual

Academic Journal of Education and Social Sciences, 8(1), 131-150.

\section{Copyright: (C) The Authors 2020}

Published by Knowledge Words Publications (www.kwpublications.com)

This article is published under the Creative Commons Attribution (CC BY 4.0) license. Anyone may reproduce, distribute, translate and create derivative works of this article (for both commercial and non-commercial purposes), subject to full attribution to the original publication and authors. The full terms of this license may be seen

at: http://creativecommons.org/licences/by/4.0/legalcode

Vol. 8, No. 1, 2020, Pg. 131 - 150

https://kwpublications.com/journals/journaldetail/MAJESS

JOURNAL HOMEPAGE

Full Terms \& Conditions of access and use can be found at https://kwpublications.com/pages/detail/publication-ethics 


\title{
Children's Drawings and the Grammar of Visual Design: Pedagogical Application of the Depiction of the "Other" in Pre-school Children's Drawings
}

\author{
Evmorfia Kipouropoulou \\ Department of Primary Education, University of Western Macedonia
}

\begin{abstract}
This paper presents an analysis of pre-school children's drawings using the methodological tool of the grammar of visual design, by Gunther Kress and Theo Van Leeuwen, in order to investigate the presence of a stereotypical representation of the "Other", or lack thereof. The construction of "Childhood" as a social category is briefly mentioned and then the evolution of children's drawings is presented. The basic principles of the grammar of visual design are documented, in the way they were evaluated during the analysis of the children's drawings. Finally, the analysis of these drawings is presented and some final comments on the representation of otherness are made. According to those results, negative stereotypes are not constructed through children's designs.
\end{abstract}

Keywords: Visual literacy, Grammar of Visual Design, Childhood, Children's Drawings, Stereotypes.

\section{Introduction - The Social Construction of Childhood}

The concept of childhood first appeared during the Renaissance and has been the object of debate and negotiation since. Nowadays, the words child and childhood are especially confusing with regard to their signification. Here a brief account of the evolution of the construction of childhood as a social category will be presented so that the term can be related to the stages of children's drawing and to the construction of subjectivity.

In ancient times the concept of the child is vague. The perception that the ancient Greeks had of the nature of childhood is confusing. However, the Greeks were passionate about the education of the youth so much so that there are many texts by Plato and Aristotle regarding the organization of education for the youth (Plato's Republic, the renowned Gymnasium etc.). The approaches in youth education do not necessarily involve an understanding of the intricacies of childhood, as we perceive them today. Childhood was not used as a distinct social category. The contribution of the ancient Greeks was, nonetheless, important: they did not discover the concept of childhood but came close to the definition of some of the characteristics ascribed to it, 2.500 years later (Postman, 1996, pp. 5-10). 
MULTILINGUAL ACADEMIC JOURNAL OF EDUCATION AND SOCIAL SCIENCES

Vol. 8 No. 1, 2020, E-ISSN: 2308-0876 @ 2020 KWP

Up to the $17^{\text {th }}$ century, childhood as a social category is non-existent, while, generally, the further back one looks into history, the lower the level of child care. The child is nothing more than an adult in miniature, and an exact copy of his or her parents at that. In Byzantine imagery, for instance, the child is generally distinguished by his or her height, according to which the child is presented to perform the relevant tasks.

Children are by rule considered to be imbeciles and belong to the same category as servants and the mentally impaired. Generally, in the Middle Ages the child participates in the adult society without their age being a restraint. The term "Childhood", therefore, seems to specify the first years of a person's life, during which time biological and mental inabilities, more so than social restrictions, deny the child the inclusion in the social sphere. Indeed there was no definition of childhood. Children functioned within the space occupied by adults.

Two important factors contributed to the change of practice concerning childhood during the $17^{\text {th }}-18^{\text {th }}$ c.: parents' tenderness toward their children, and especially that shown by the mother, and the interest of moralists and "pedagogues" of the time in children's physical and mental/psychological wellbeing. From the $18^{\text {th }} \mathrm{c}$., when educational institutions are established, childhood begins to be defined through the institutions of family and the school. A very important consequence was the limitations on the child's freedoms (Aries, 1997). Children were, according to moralists, god's weak creatures in need of edification and protection (Aries, 1997).

The interest in childhood is not the result of an abrupt sensitization of the period's intelligentsia toward childhood, but a result of social, political and economic conditions, such as the decrease of childhood mortality -and thus the parents' emotional investment in the relationship with their children, the decrease of child labor and the need for children to be placed under the control of adults. In relation to the above, the maternal and paternal stereotypes of the period are constructed.

During the $19^{\text {th }}$ century and the beginning of the $20^{\text {th }}$, a supportive climate is created for the establishment and progress of institutions concerning the child. However, it remains a fact that during the $19^{\text {th }} \mathrm{c}$. in particular the child was still considered as a future adult, yet not as an adult in miniature, as had been the case during the Middle Ages.

With the advent of the $20^{\text {th }}$ century childhood was considered an inalienable right of every human being. Consequently, the institution of education, which delimits the ages of childhood, and the organized social welfare for children, through parental and state obligations, the focus is placed on the establishment of institutions relative to childhood. Besides the school, the state now organizes and controls a great sector of actions that regard childhood and aim at improving children's quality of life, yet also controlling the ideology surrounding the child. As a result, a tolerance of childhood within society is institutionalized and childhood is considered as a period toward adulthood.

It is evident, thus, that one of the most important reasons for the construction of the category of "Childhood", which was also a result of the social changes after the industrial revolution, was the institutionalization of compulsory education. The importance lies in the role that education plays in the construction of society, in relation also to the already established institutions, such as the family. What is more, education now defines the age limits of the category "child" and ascribes to it the characteristics that separate it from the other age categories. The socialization of the child before the great changes brought about by the industrial revolution was the responsibility of the family, which was the basic unit of society. The family 
MULTILINGUAL ACADEMIC JOURNAL OF EDUCATION AND SOCIAL SCIENCES

Vol. 8 No. 1, 2020, E-ISSN: 2308-0876 @ 2020 KWP

provided the child with knowledge for their future profession (which was generally hereditary), yet it also provided for the child's moral education. Compulsory education for all, under the new circumstances, is called upon to compensate for the family's inability to provide the young person with the relevant skills, since society's demands have changed and exceed the limits of the family. On the one hand, therefore, school becomes an important socializing factor and, on the other, it assists the family, though the teacher, in the moral education of the child. The entire educational mechanism is structured in such a way to ensure that knowledge is provided along moral messages. The family, while not set aside, now complements, and shares responsibility for, the moral edification of the child.

The most important consequence of compulsory education is perhaps the fact that its institution concerns a defined age group, which it separates from other age groups, and attributes certain characteristics to it. The child enters a frame of specific obligations and responsibilities that are common and do not easily change for each individual child. The most important of these common characteristics that unify childhood and make it a special and separate age group are economic dependence, ethical inexperience, and the child's malleable character (Makrinioti, 2003, pp. 30-31, Tzimkas, 2008).

Postman (2001) argues that during the construction of the child's identity, this being the equalizing medium of communication par excellence, it dissolves age, and other, limits that had been granting access to information and knowledge and abolishes knowledge that had been restricted to the world of adults (pp. 141-145). The factors that delimit the category of "childhood" are absent. Consequently, the concept of "childhood innocence" is banal and only reminiscent of the charm that childhood had, propositions that have been criticized.

\section{Children's Drawings as Semiotic Act}

The interest in children's drawings was initially expressed toward the end of the $19^{\text {th }} \mathrm{c}$., first by psychology and afterwards by education, sociology and aesthetics. The emergence of the socalled children's art was significantly influenced by the research and scientific interest in childhood, by the evolution of the plastic and graphic arts and by the dissemination of paper and graphite, while the emergence of new materials and mediums modified the style of children's art (Mèredieu, 1981, pp. 12-18).

In the present study we approach children's drawings from the perspective of social semiotics, treating them as a product of visual writing which is informed by contemporary social interpretations within a given context and cultural influences. The social and ideological influence define children's expression already in the first stages of childhood. Children develop within their contemporary environment and, influenced by the power of the image, they do not simply reproduce forms, but put in paper what they see in the particular way they perceive it and by using the materials available to them. Children's drawings are studied in the frame of social semiotics as a cultural product (Andreou et al., 2005, pp. 51-54, Vamvakidou et al., 2009).

The child of 3-4 years of age disengages from the work of art as soon as the latter is completed. The emphasis on the young child's work is rather placed by adults. The child is more interested in the movement. The immediate and spontaneous nature of children's drawings is apparent in scribbles, or "doodles". As the child develops, so the movement becomes slower and more attentive. The development of drawing is associated with the development of the writing 


\section{MULTILINGUAL ACADEMIC JOURNAL OF EDUCATION AND SOCIAL SCIENCES}

Vol. 8 No. 1, 2020, E-ISSN: 2308-0876 @ 2020 KWP

skill. During their school years, when children begin to write, drawing is put aside. However, during that same period children discover new ways of writing and drawing.

The child makes use of a whole repertoire of signs often of symbolic significations, such as the sun, a house, a tree, a boat. Children's drawings begins as simple shapes - circle, square, triangle, and little by little their combinations produce various forms, as happens with the mantadpole that later evolves in a sun with a face. At a young age, children do not discern between sign and signified. Such discernment is apparent during the school years through the influence of adults and the cultural environment (de Mèredieu, 1981, pp. 18-39).

Scribbling/Doodling is mostly a kinetic activity. When children begin to realize that movement creates a trace, they will repeat the movement for pleasure. The realization that, through this movement in scribbling/doodling, the trace/sign is retained is very important.

The stages of scribbling/doodling, according to graphologist and psychologist $\mathrm{M}$. Bernson (Pantzaridou, 2009) are the following:

- Vegetative/Phyto- kinetic stage: 18 months. Children's drawings are basically circularhelical, pencil is not lifted from the paper.

- Representational stage: 2-3 years of age. Tentative depiction of forms. Lines become non-continuous and there is verbal commentary.

- Communicative stage: 3-4 years of age. An attempt at writing is depicted as the influence of the environment is important. At the same time the child draws trying to imitate letters by adults. 
MULTILINGUAL ACADEMIC JOURNAL OF EDUCATION AND SOCIAL SCIENCES

Vol. 8 No. 1, 2020, E-ISSN: 2308-0876 @ 2020 KWP

Drawing with single-form depiction

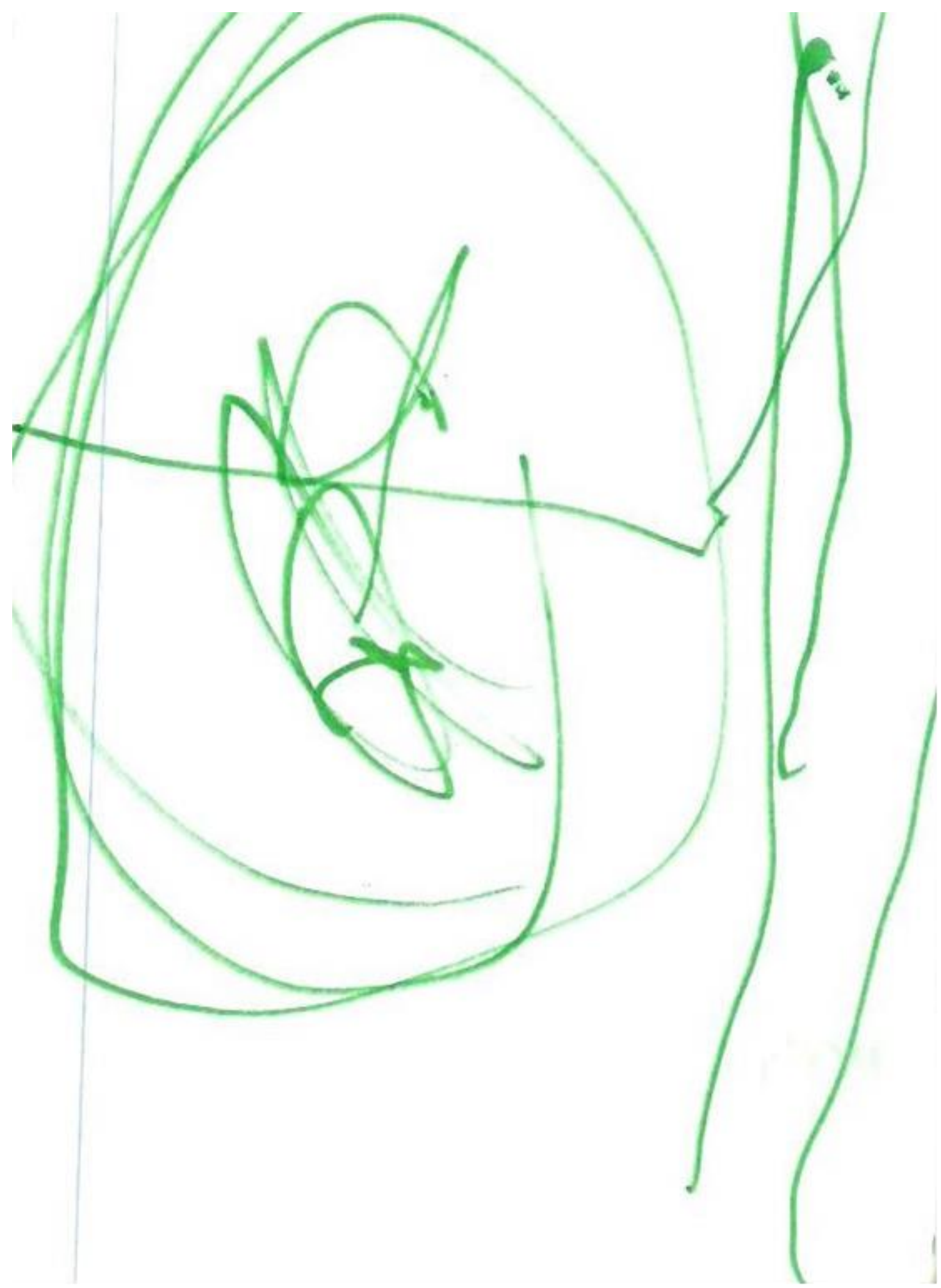


MULTILINGUAL ACADEMIC JOURNAL OF EDUCATION AND SOCIAL SCIENCES

Vol. 8 No. 1, 2020, E-ISSN: 2308-0876 @ 2020 KWP

Attempt at depicting forms with adult participation

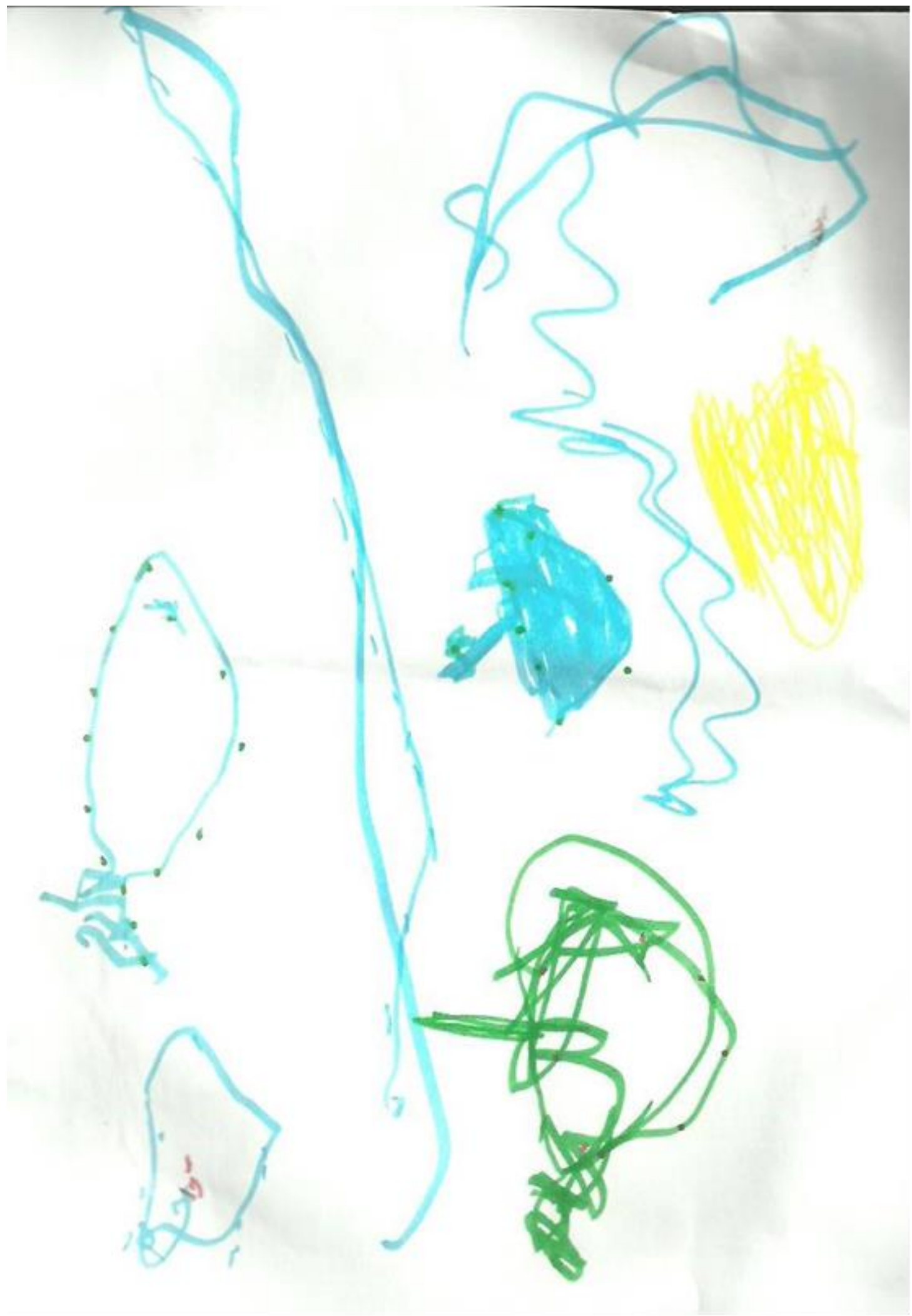


MULTILINGUAL ACADEMIC JOURNAL OF EDUCATION AND SOCIAL SCIENCES

Vol. 8 No. 1, 2020, E-ISSN: 2308-0876 @ 2020 KWP

\section{The Study}

The research was conducted in the context of a university course entitled Art and childhood with the help of the students who gently gathered children's drawings. The research hypothesis concerned the construction of a stereotypical representation of the "other" and the emphasis and the emergence of the "national self". Therefore, the research questions were:

- How the national self and the "other" are represented through drawings?

- In what ways the national self is represented as superior to the "other" according to the grammar of visual design?

\section{The Sample}

The sample was consisted of pre-school age children's drawings who were asked to draw a design under the only instruction "Depict a Greek, a Chinese and an African person", but without any other guidance, with the aim to trace elements of stereotypical depiction, or lack thereof. It was also asked of the children to recount the story their drawing depicts, to the extent that this was possible, which would make the drawings multimodal texts. Ten drawing were gathered. For the purposes of the present paper, six of these drawings are presented and analyzed using the grammar of visual design, five drawn by girls and one by a boy of pre-school age. The other four drawings were drawn by children at a young school age.

The drawings were analyzed using the grammar of visual design by Gunther Kress and Theo Van (Leeuwen, 2006). The research is considered a work in progress.

\section{Social Semiotics - Basic Principles of the Grammar of Visual Design by Gunther Kress and Theo Van Leeuwen}

The work of Gunther Kress and Theo Van Leeuwen is part of Social Semiotics. The Prague school (1930-40), the Paris school (1960-70) with Barthes, and the movement of Social Semiotics that launched in Australia by the linguist Halliday - to which the work of Kress and Leeuwen subscribes, comprise the three schools of Semiotics that have applied the concepts of Linguistics on non-linguistic modes of communication (Kress \& Leeuwen, 2006, pp. 1-3).

Based on the theoretical assumptions of the linguist Halliday, Kress and Leeuwen argue that just as the grammar of language describes the way in which words are put together to form phrases, so the grammar of visual design describes the combination of depicted individuals, places and objects in visual sentences (Kress \& Leeuwen, 2006, p. 1). Of course, the analogy that is attempted between visual structures and language does not mean they are identical. Visual, as much as linguistic, structures produce meanings, which aim at different interpretations of experience and different forms of social interaction. Kress and Leeuwen claim that visual literacy becomes more and more imperative in everyday life and especially in the work place. The establishment of visual literacy rules does not imply a decrease in creative freedom, just as literary expression is not impoverished by learning to use the grammar rules of a language.

Like linguistic structures, visual structures aim at specific interpretations of experience and the various forms of social interaction. Meaning derives from culture and therefore the fact that we can "say" certain things either linguistically, using an image or creating multimodal texts, is culturally and historically specific (Kress \& Leeuwen, 2006, pp. 2-4).

In each semiotic system and in the grammar of visual design, we trace 
MULTILINGUAL ACADEMIC JOURNAL OF EDUCATION AND SOCIAL SCIENCES

Vol. 8 No. 1, 2020, E-ISSN: 2308-0876 C 2020 KWP

$\checkmark$ The ideational function, the ability of semiotic systems to represent/depict objects and the relations among them outside their representational system, in what we call semiotic landscape.

$\checkmark$ The interpersonal metafunction, which depicts the relations between the producer of the sign and the receiver of the sign.

$\checkmark$ The textual metafunction, the ability of the semiotic mode to form texts, that is complexes of signs that communicate with one another (Kress \& Leeuwen, 2006, pp 40-44)

The image reproduced by children as non-verbal communication functions differently from language and gives us the opportunity for an open-ended reading. Despite the fact that it is encoded, does not impose on the receiver/reader immediately, but organizes messages in a multi/poly-semiotic way. In this respect, semiotics looks for codes, analogies to objective reality, cognitive and perceptual ability and cultural awareness.

\section{What we Look for in the Analysis of Visual Design}

Criterial aspect of the object: It refers to the interest shown by the creator of the visual design in some of the aspects of the object which he or she uses in semiosis in order to represent it (Kress \& Leeuwen, 2006, p. 7).

Semiotic landscape: This involves the context of the full range of forms and modes of public communication available and the context of their uses and values.

The choice in distance between forms and receiver

Are the forms turned toward the receiver (personal contact) or not?

Is the perspective of the image given from an angle (signifies the absence of participation from the part of the subject) or is it frontal (denoting participation)?

Low angle: shows lack of authority

High angle (the image is situated as if the spectator looks at it from high above): shows the authority of the spectator

Same level of form - receiver: a relation of equality between creator and spectator

The image shows the "back" side of those depicted (abandonment of lack of trust)

Perspective gives a sense of verisimilitude

Forms/Shape/Size

Is there similarity to human forms?

Is emphasis placed on limbs and faces?

Is there any scribbling? Is the form discernible?

Are connotations in visual representations formulated by educational discourse at school or by the family that expresses a public discourse?

\section{Space}

Use of space: interior/exterior, natural/urban etc.

Which of the forms used are placed at the center, which on the left and which on the right side of the image? According to the grammar of visual design, the most important information is placed at the center of the image, the "given-stable" cognitive material on the left and the new material, the new information, on the right side of the image.

Is the image personal or impersonal? 
MULTILINGUAL ACADEMIC JOURNAL OF EDUCATION AND SOCIAL SCIENCES

Vol. 8 No. 1, 2020, E-ISSN: 2308-0876 C 2020 KWP

Is there any framing or not? (are the elements of the image connected or not, do they correlate or not?). The absence of framing focuses on individuality and the differentiation from the group. Rigid/strict framing of one element shows its separation from the others in an image.

Movement/ Position/Direction

Are forms presented standing still or moving?

Is there any action or some kind of scenario in the child's drawing (internal narrative look)? In standing representations the external narrative look is observed. If the human form is given in a frontal stance, it signifies the demand for acknowledgement. Sidelong stances signify offer. If the forms look at the spectator directly, they aim for immediate contact and presumably the identification of the recipient according to the context of the image.

Objects that are placed at the top of the image reflect the ideal (what we could have been) while elements found at the bottom are more practical and informative, down to earth (what we are).

\section{Modality}

The different forms of modality define the "reliability" of the depicted object, if this is given as closely as possible to the presentation of the real object it represents. The interpretations of the forms of modality are social as they depend upon what is considered real within the social group that the visual image regards (or is made by).

The most important criterion in what we esteem real or not is based on the appearance of objects, and on how the object that we can see "out there" in a specific situation is reflected by what we see in its visual representation. In the grammar of visual design, the forms of modality comprise of:

Color

$\checkmark$ Color and its gradation (white and black, as well as single colors are of low modality)

$\checkmark$ Depth (the central perspective is of high modality)

$\checkmark$ Shimmer/shine

$\checkmark$ Lighting

Colors are forms of modality and define the "reliability"/ "credibility" of the depiction of an object, if this closely reflects the real object being depicted (Kress \& Leeuwen, 2006, pp. 120165).

Sub-categories of colors are classified as warm (yellow, the warmest color) and cold (blue, light blue, black), and as lacking color, according to the classification by Kandinsky. Nowadays, children are presented with a variety of colors and materials that they can use to express themselves creatively, so much at school as at home.

Classification of Colors (according to Kandinsky, 1981)

Yellow: typical earthly color

Blue: the color of the sky, light blue expresses tranquility

Green: it expresses peace and tranquility, it does not express liveliness nor passion

Light red: warm color, it expresses energy

Deep red: cold color

Purple: it expresses sickliness

White: it expresses the harmony of silence

Black: absolute silence, without hope nor future 
MULTILINGUAL ACADEMIC JOURNAL OF EDUCATION AND SOCIAL SCIENCES

Vol. 8 No. 1, 2020, E-ISSN: 2308-0876 ๔ 2020 KWP

Grey: a dead-end immobility

\section{Signature}

The use of a signature and/or another sign at the top of the drawing expresses the "ideal" of the composition, while the real and specific elements of the composition are found at the bottom.

\section{Pedagogical Implementation-Analysis}

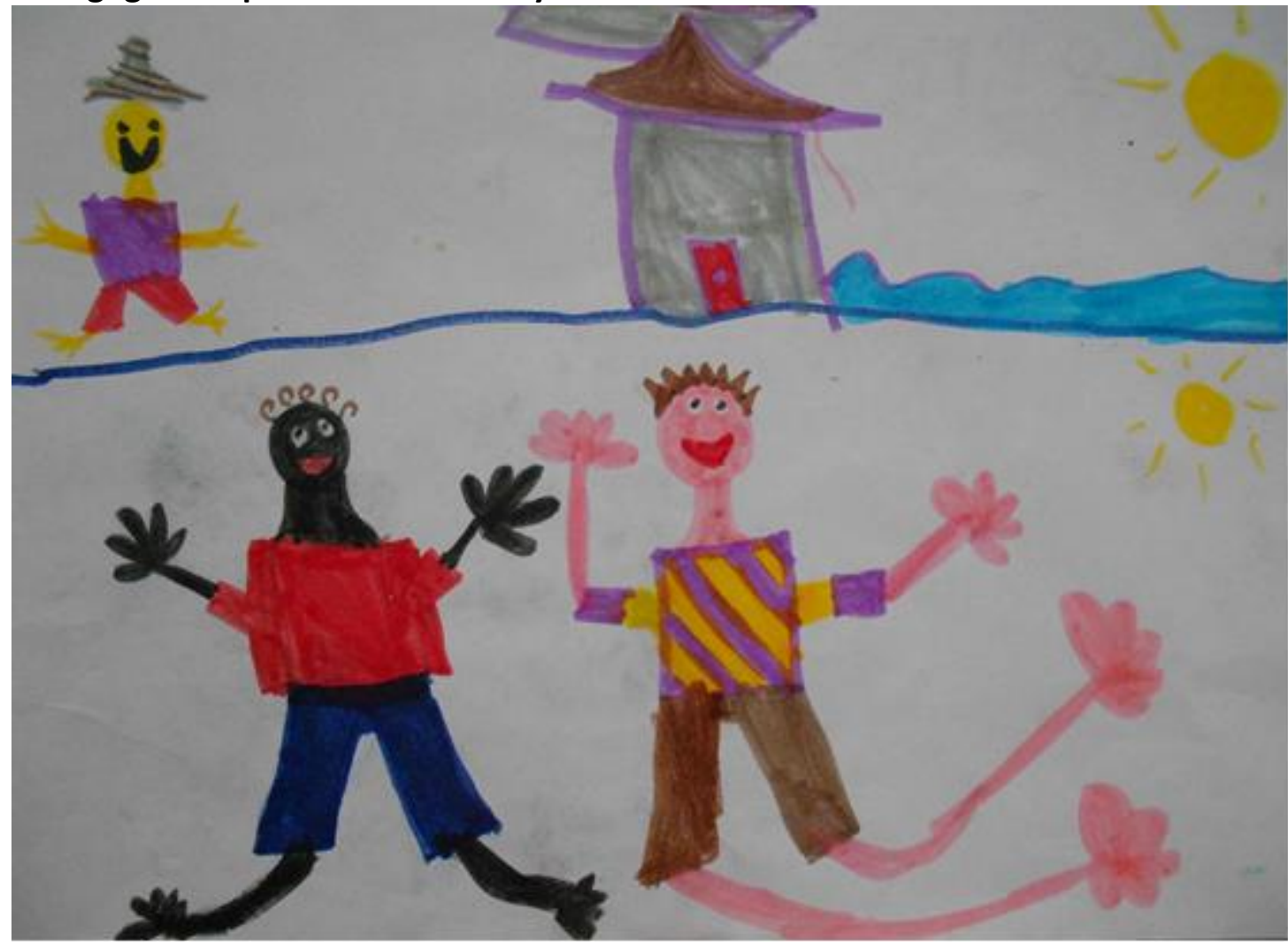

Boy, five years old

The child who made this drawing is five years old and it was drawn in an A4 piece of paper after our instructions, while the choice of materials and colors were his. If we study this drawing we observe that the action/plot takes place throughout the work and not simply in one isolated point, as there is no central, but a diffused action. A house near the sea is depicted, which, in relation to the movement of the figures, makes the scenery look like that of a walk or a field trip. The criterial object in this work is rather the figure of the African due to the use of the color black. The figures are immediately facing the receiver and at the same level as the spectator. The depiction is not given within a framework, and all figures are presented in rigorous movement. The visual representation is characterized by high modality due to the small divergence from any realistic element. The signature is placed at the back of the page, which indicates that the child does not seek any acknowledgement by using his identity. The sensation that this work causes is a positive one and it is evident that no negative stereotypical signified is depicted, since all the figures are represented equally even when it comes to size. The figure of the Chinese is drawn at a higher level. The only rather stereotypical element is his traditional hat. 


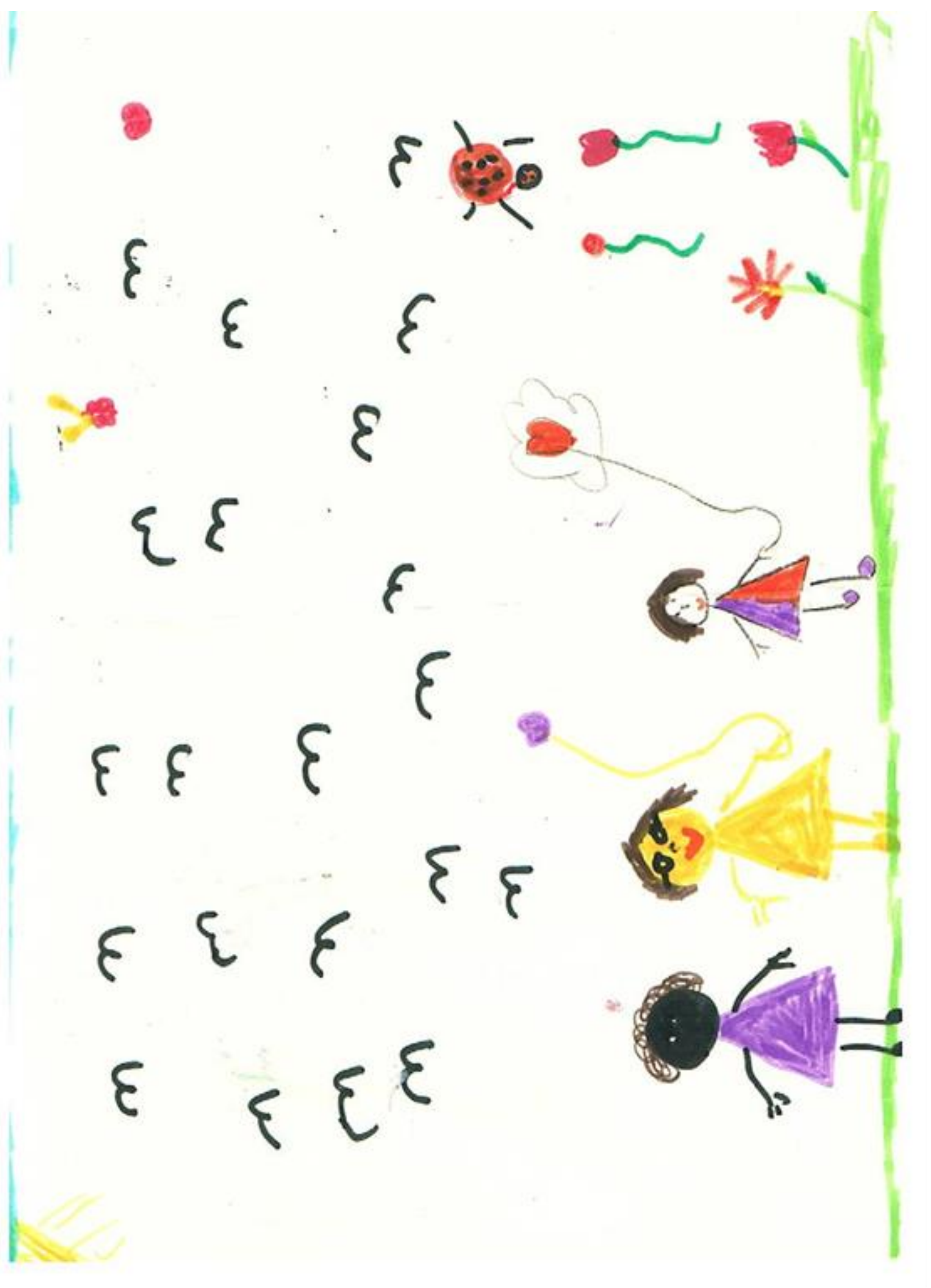

\section{Girl, Pre-school Age}

In the above drawing we can discern three figures of girls, an African, a Chinese and a Greek girl. The figures are immediately facing the receiver, and at the same level as the spectator. The space is exterior, and natural. The faces are female and the Greek girl is physically smaller than 


\section{MULTILINGUAL ACADEMIC JOURNAL OF EDUCATION AND SOCIAL SCIENCES}

Vol. 8 No. 1, 2020, E-ISSN: 2308-0876 @ 2020 KWP

the other two figures. The modality is high, with many bright colors. The Chinese and the Greek girls hold a balloon, while the African girl does not, because "in Africa children are poor and cannot afford balloons", as the drawing claimed. There are many birds above the figures. On the right side of the drawing there are butterflies and ladybugs, since the drawing was done during Easter. The signature is placed at the back of the page, as dedication. The figures are depicted as nearly equal, with that of the Greek girl slightly smaller physically.

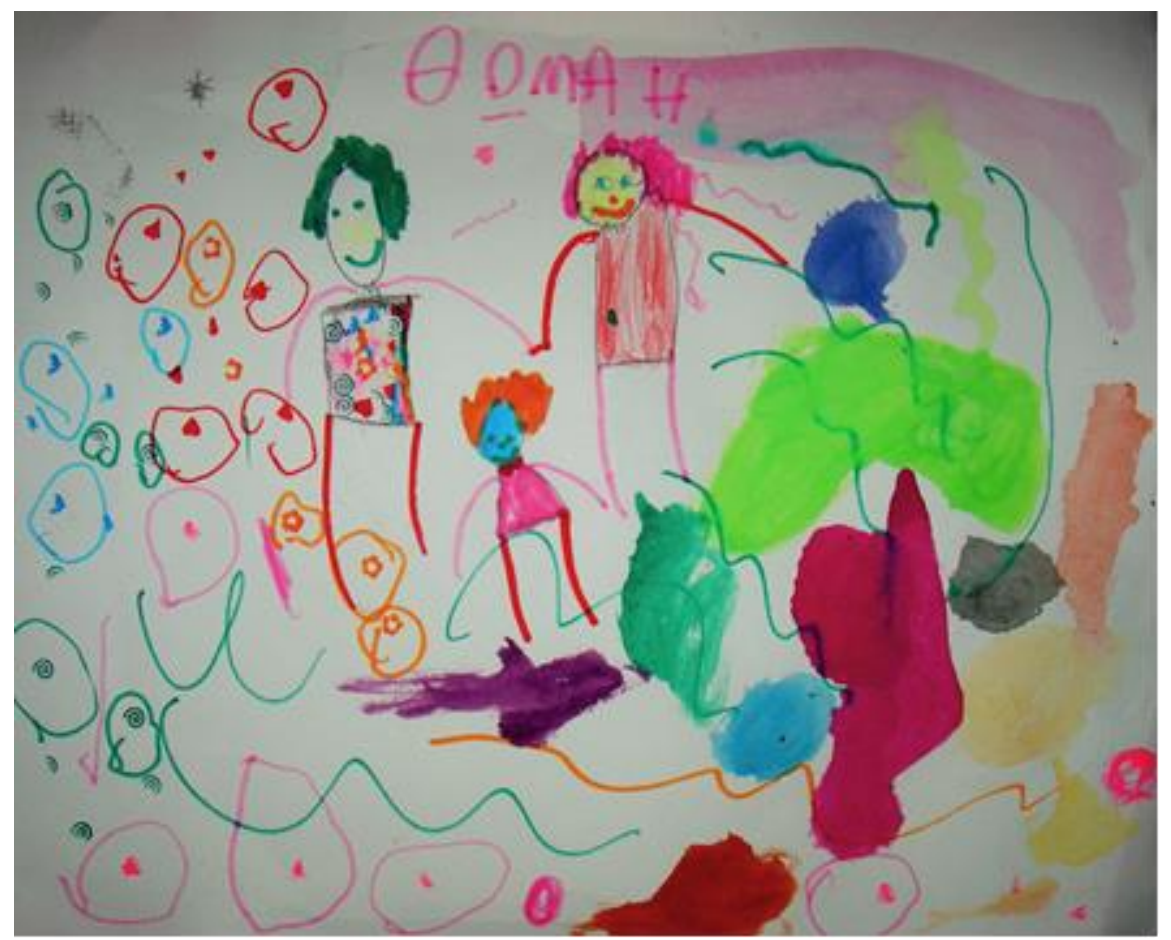

Girl, five years old

In the above child's drawing we can discern three figures, two of women and one of a man. The girl who drew it does not know where China or Africa are. The Greek man is the left male figure, the Chinese woman is in the middle, with the light-blue face, and the African woman is on the right. Nothing is earthly, nothing steps on the ground, everything is colorful and flying. The color black is absent as the girl claimed that it is her worse color, while fuchsia dominates as the girl's favorite. Her name is written with big fuchsia letters above everything, which expresses the ideal, and the best stamps are framed by color and discerned as "good drawing". The Greek man and the African woman dance. 

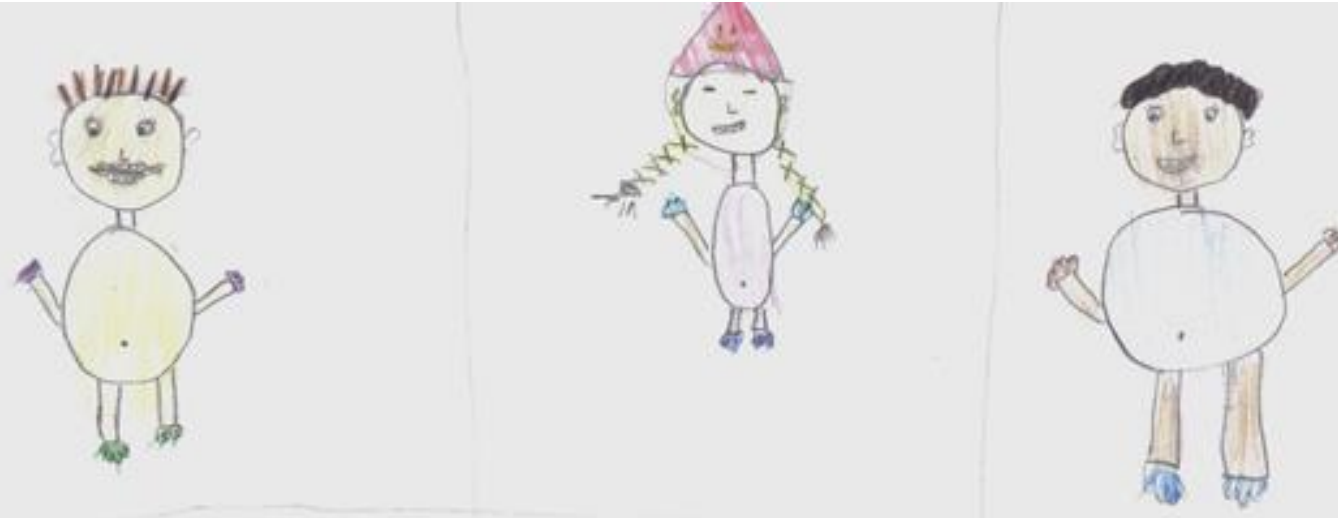

Girl, five-and-a-half years old

As observed in the drawing, the girl -who is of Greek-Arabic descent- has placed the three figures in a certain order, probably according to instructions.

Initially, she separated the piece of paper in rigidly framed parts, and placed the figures at almost the same level at the top. This indicates how the three figures become equal, even though she discerned them as separate and she perceives them as ideal.

The Greek man is placed on the left part of the piece of paper, which signifies the given element. He has a moustache, "because her father does", "and spiked hair, because all her classmates in the first grade do", as she claimed.

The Chinese woman is placed second, looks smaller physically and is at a higher level than the others in the center. Even though the girl drew the Chinese woman with what she perceived as Asian eyes, which is an important element, she made her blonde with white skin. The African man is given third and looks physically bigger than the other two and has darker skin. He is placed on the right side of the drawing as the new information. The modality is relatively high as the figures are discernible and framed. The girl placed emphasis on the faces and their characteristics, making them similar to actual human forms.

The figures are static. They do not move, except with their upper limbs. They are drawn with clarity and are immediately facing the spectator, creating a personal connection with them. They are placed higher than the receiver, which denotes a relation of inequality. The girl might have placed the figures there on purpose, perceiving them as ideal.

There is no scribbling, and the drawing is neatly done, with colors going outside the lines only slightly. 
When asked whether the colors of the clothes were specifically chosen, the girl answered that they were randomly picked. We can observe that she used green and blue for the Greek and the African men, which denotes peace and tranquility, while the Chinese woman wears a pink dress.

The signature is absent. The girl did not wish to say anything else about her drawing, except that she "made them happy".

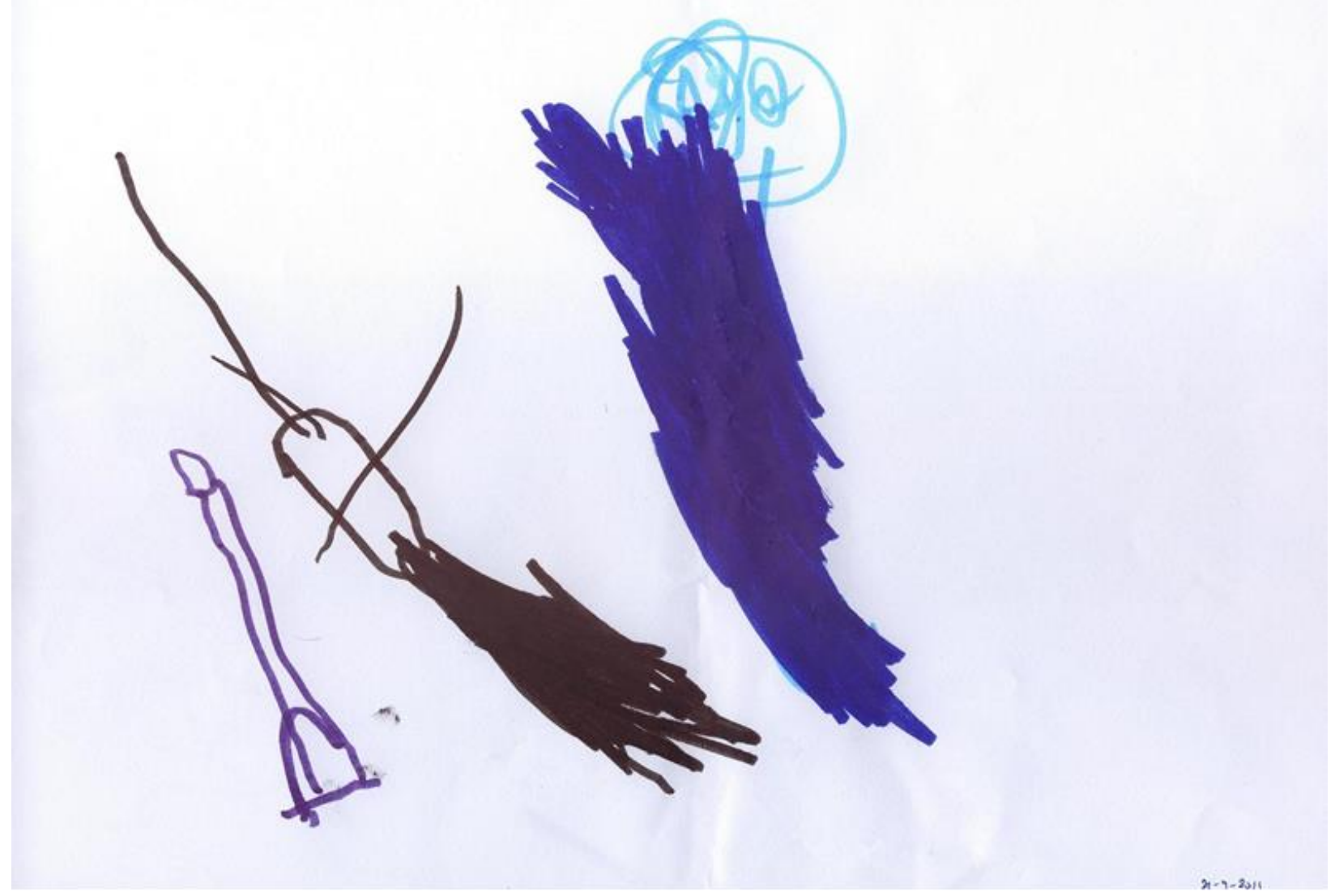

Girl, three-and-a-half years old

Due to the girl's young age, the designs are minimalist and of low modality, as the figures are not easily recognizable, they lack detail -except for the third figure in which the eyes and the mouth are discernible. The figure on the left is quite small, the one in the middle is slightly bigger and that on the right is the biggest of all. There is a climactic growth regarding size.

To begin with, the Greek on the right part of the drawing is adequately formed and comprises of basic shapes (circle, parallelogram, semicircle). In the next form, and more so in the third, a more realistic depiction is attempted, even though filling up these last two figures with color deprives them of many elements present in the first one.

It seems that the girl has overcome the stage in which humans are depicted as tadpoles. During this communicative stage (ages 3-4), the girl lifts the marker as she draws with discontinued lines and forms different elements of the human body. She is happy to scribble/doodle as she fills the figures with color, since motion is what is important at this stage. 
The first figure (a Greek woman) has an oval, egg shaped, head, a parallelogram for a body and a semicircle as a skirt. What is more, the ground where she steps is also drawn. The second figure (the African) is done more freely, with a bigger head. The girl does not hesitate to rotate the piece of paper and draw from another angle. She puts more details in this figure than in the Greek one, probably because the Greek seems more familiar and predictable, while the other two forms might be more interesting to her. When the girl draws the African figure, she places his upper limbs on its head, which is typical of her age. The Chinese figure is the largest figure and displays many characteristics, a round head, more realistic than the other two figures, with eyes, a nose and a mouth. Colors are bright for the Greek and the Chinese, while being her favorite. The only color that is related to actual skin color is the one used to depict the African.

The girl drew a Greek woman, who wears a skirt, and with whom she probably relates as far as sex and nationality are concerned. The other two figures do not display a characteristic of sex. However, there is no skirt drawn for these. The location is not defined, we do not know whether it is interior or exterior.

There is no attempt at writing, which is expected at her age. The only letter the girl knows how to write is the initial of her name, $\mathrm{X}$, however she did not use it as a signature. All three figures are drawn facing the receiver, which signifies the demand for acknowledgement and communication. There is nothing else surrounding the figures. All three figures are drawn relatively low on the page, seem to stand firmly on the ground (they are depicted as the girl thinks they really are). As far as discriminating against difference, the Greek, rather than the African or the Chinese, seems to be differentiated from the others. The Greek is drawn without any extravagance, almost dull, while the other two figures are done freely, with detail and more elements.

Finally, the figures are not framed, so the Greek is not separated from the other two figures, all are situated in the same space, and the other two figures are given more space. 


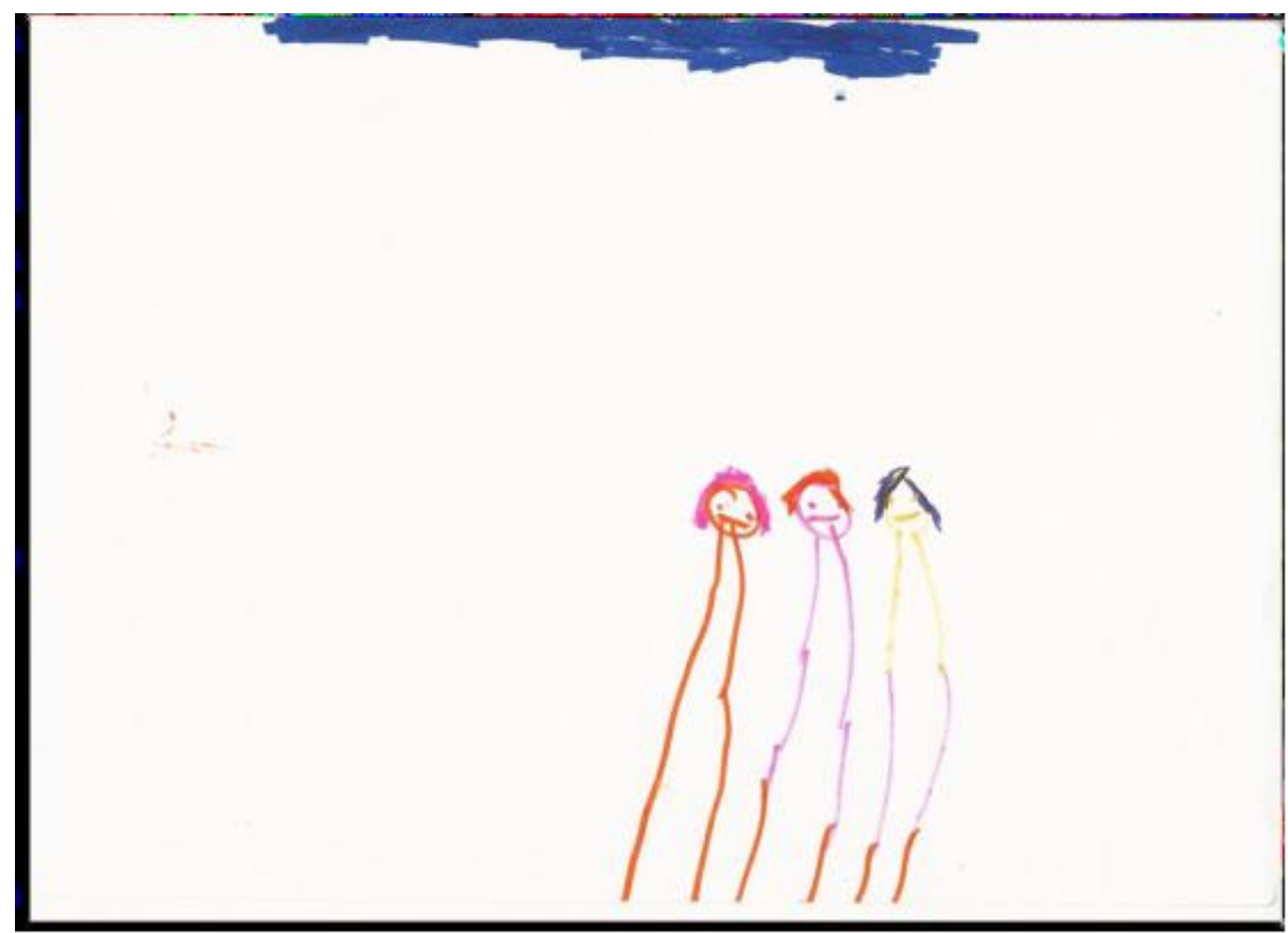

Girl, four years old

The girl starts by drawing a little person in yellow who, she claims, is the Greek. She moves on to draw the Chinese in pink. The Chinese is larger in size than the Greek, who is next to him, and as soon as the girl realizes, she draws lines further down their lower limbs in order to make them equal in size. Then she draws the African, whom she carefully tries to depict at an equal size. The figures are full-body, facing the receiver and of equal size, and their positions are at the same level as the spectator. They are drawn on the right side of the piece of paper, which signifies the new element -three new forms according to the child. At the top of the sheet the sky is drawn, while nothing else is depicted in the surrounding space. The figures are smiling.

\section{Discussion}

Social representation is a mechanism that provides individuals with the opportunity to ascribe meaning to anything that is unknown and unfamiliar and to evaluate such meaning. Every social representation comprises of a mixture of meanings or ideas and images (Potter, 2005, p. 202). The processes of representing or ascribing meaning to the "other" are ones through which communities are constructed and the various forms of "we" and "them" are created, which formulate any racist discourse (Wetherell, 2005, p. 259).

The discourse of stereotypes and biases, which is based on exaggeration, evaluation and repetition, is expressed as the sum of concrete perceptions of the characteristics of the "other" and is constructed as social discourse around the "other" who is seen as a collective subject. Children, through their interaction with their parents, and the classifications and verbal descriptions of adults, perceive very early on the verbal social categorizations and construct the 
MULTILINGUAL ACADEMIC JOURNAL OF EDUCATION AND SOCIAL SCIENCES

Vol. 8 No. 1, 2020, E-ISSN: 2308-0876 @ 2020 KWP

image of the "other" accordingly, in the same way they learn the distinction between "right/wrong" (Gotovos, 1992, pp. 20-22).

The identity of the child is initially constructed through mechanisms of control by the family, but also by public discourse, whether this refers to the field of science, the legislative or political discourse, or that of the media. The child is acknowledged through the practices and knowledge based on which they construct their identity. All such practices create new forms of authority and guardianship of childhood at a mostly symbolic level (Makrinioti, 2001, pp. 35-36). Considering this and responding to the initially posed question relating to the stereotypical visual representation of the "other" in children's drawings, we can claim that the children in this study do not produce any positive nor any negative stereotypes regarding the national self and the "other". In the present drawings the depiction of the "other" is done without any categorizations or evaluations. The figures are rather equal and smiling, facing the spectator as if in communication with them, and they present medium to low modality due to the relevant developmental stage of these pre-school children. Anyway, children at such a young age do not discern the relationship between signifier -signified. This distinction is made usually during the first years of school through the influence of adults and the cultural environment (De Mèredieu, 1981, pp. 18-39). Bernstein (1989) talks about pedagogical/educational subjects and the transmission, though education, of certain forms of culture (pp. 161-162, 181-183). The individual is a constructed subjectivity throughout the educational process, and even before that, which is in constant transfiguration under the impact of the "typical educational practice" within the family and the community, and not only within the school environment.

Pre-school aged children bring with them the cultural burden of their family's history and its narratives, however they have not yet felt the impact of the educational practice on the construction of their subjectivity. In these children's drawings, the "other" is represented as an equal to the "known"/ "familiar". Of great research interest would be a future comparative analysis between drawings of pre-school and primary school children.

The limitation of this study is the small sample size. However, it sheds light on how young children represent otherness through a very important -for this age- semiotic code, such as drawing. Within the framework of multi-literacy, the analysis of children's drawings according to the grammar of visual design could contribute to the detection of attitudes and representations of pre-school aged children. As Kress (1989, pp. 90-95) claims, the student is an active, not a passive recipient. Even if the final outcome is children's complete socialization under the rules, values and meanings of the social group they belong to, their active participation in the educational process and in the acquisition of language places them in a complete different position from that of a passive reception of language learning. Visual literacy precedes language and comprises the corner stone of thought, as research data confirm regarding the understanding of images and the evaluation of visual signs by children of a very young age, leading to the conclusion that children initially see and recognize images a long time before they start talking. Thus, during the linguistic culture of a pre-school child, teaching visual literacy is important as it is an attractive means that promotes the smooth transition to linguistic literacy and a necessary communicative practice that demands to coexist with the linguistic one in the modern educational environment (Goria, 2014, p. 72). For this reason, we need to focus our attention to the student's actions, since these express three seminal points: the taxonomic 
MULTILINGUAL ACADEMIC JOURNAL OF EDUCATION AND SOCIAL SCIENCES

Vol. 8 No. 1, 2020, E-ISSN: 2308-0876 @ 2020 KWP

system of the child with its cognitive, perceptual, cultural and social consequences, the understanding from the part of the child of the systems of adults, and their mutual conflict.

\section{References}

Andreou, A., Golia, P., \& Kassidou, S. (2005). The Turk and the Greek in 'pre-school children's drawing': Semiotic analysis of the national 'other' in children's drawings. In A. Kiridis \& A. Andreou (Eds.), Aspects of otherness (pp. 51-72). Athens: Gutenberg.

Goria, S. (2014). Understanding and production of multi-modal texts during pre-school age: The case of map. (Unpublished doctoral dissertation). University of Thessaly, Volos.

Gotovos, A. (1996). Racism: Social, psychological and educational aspects of an ideology and practice. Athens: GSFY (General Secretariat for Youth).

Konstantinidou, S. (2009). The image of the child in the photographic work of Voula Papaioannou. (Unpublished doctoral dissertation). AUTH, Thessaloniki.

Makrinioti, D. (Ed.) (1997). Childhood. Athens: Nisos.

Tzimkas, G. (2008). Childhood in educational manuals (1950-2000). (Unpublished graduate research paper). AUTH, Thessaloniki.

Vamvakidou I., \& Golia P. (2009). "Representations of women in imaginery: Primary Education textbooks of history". Modern Education, 158, 139-153.

\section{Translated in Greek}

Aries, P. (1990). Centuries of childhood. (Anastasopoulou, Trans). Athens: Glaros.

Aries, P. (1997). Aspects of childhood. In D. Makrinioti (Ed.), Childhood pp. 47-54. Athens: Nisos.

Bernstein, B. (1989). Educational codes and social control. (I. Solomon, Trans). Athens: Alexandria.

Gombrich, E. H. (1998). The chronicles of art. (L. Kasdagli, Trans.). Athens: National Bank of Greece Cultural Foundation.

Kandinsky, W. (1981). Point and line to plane. (E. Malaki-Stathaki, Trans.). Athens: Dodoni.

De Mèredieu, F. (1981). The design of the child. (D. Psichogios, Trans.). Athens: Ipodomi.

Makrinioti, D. (2003). Childhood Worlds. Topika d.Athens: nisos.

Postman, N. (1997). The disappearance of childhood. (K. Metaxa, Trans.). Athens: Nisos.

Potter, J. (2005). Attitudes, social representations and discourse. In M. Wetherell (Ed.), Identities, groups and social issues (pp. 175-253)] (N. Mpozatzis, Trans.). Athens: Metaixmio.

Wetherell, M. (2005). Intergroup relations and the social psychology of racism. In M. Wetherell (Ed.), Identities, groups and social issues (pp. 253 -335). (N. Mpozatzis, Trans.). Athens: Metaixmio.

Burr, V. (1995). Social constructionism. London: Routledge

Kress, G. (1989). Linguistic processes in sociocultural practice. Oxford: Oxford University Press.

Kress, G. (2010). Multimodality: A social semiotic approach to contemporary communication. London: Routledge

Kress, G., \& Van Leeuwen, T. (2006). Reading images: The grammar of visual design. London: Routledge.

Sarup, M. (1984). The structuring of subjectivity. In Marxism/structuralism/ education. (pp. 7185). London: Falmer. 
MULTILINGUAL ACADEMIC JOURNAL OF EDUCATION AND SOCIAL SCIENCES

Vol. 8 No. 1, 2020, E-ISSN: 2308-0876 @ 2020 KWP

Internet Sources

Dragona, T. (2007). Stereotypes and biases in Keys and copy keys, MINEDU (Ministry of Education and Religious Affairs), University of Athens. Retrieved from http://repository. edulll.gr/edull//retrieve/3227/933.pdf

Pantzaridou, D. (2009). Children's drawings as tools for the evaluation of the psychological and emotional condition of pre-school children, Aisthetiki Agogi (Aesthetic Education), 15, 2-28. Retrieved from https://docs.google.com/document/d/1-WliAfDImJAzpfcfAFzft3EZ_ 84Ac4WgE80pT8syvKg/edit 